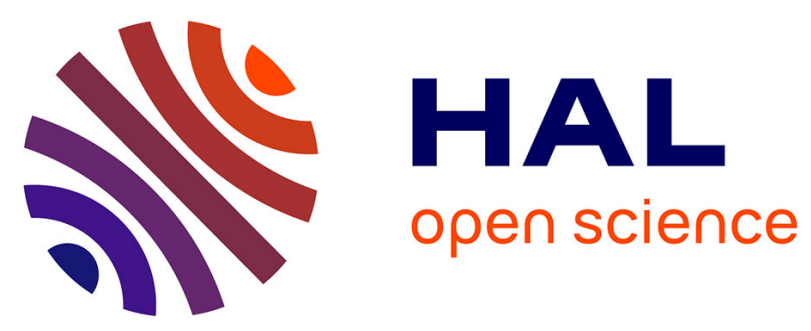

\title{
Theoretical Investigation of Phosphinidene Oxide Polypyridine Ruthenium(II) Complexes: Toward the Design of a New Class of Photochromic Compounds.
}

Olivier Vieuxmaire, Rémi E. Piau, Fabienne Alary, Jean-Louis Heully, Pierre Sutra, Alain Igau, Martial Boggio-Pasqua

\section{To cite this version:}

Olivier Vieuxmaire, Rémi E. Piau, Fabienne Alary, Jean-Louis Heully, Pierre Sutra, et al.. Theoretical Investigation of Phosphinidene Oxide Polypyridine Ruthenium(II) Complexes: Toward the Design of a New Class of Photochromic Compounds.. Journal of Physical Chemistry A, 2013, 117 (48), pp.1282130. $10.1021 / j p 408898 n$. hal-00915275

\section{HAL Id: hal-00915275 \\ https://hal.science/hal-00915275}

Submitted on 15 Jun 2020

HAL is a multi-disciplinary open access archive for the deposit and dissemination of scientific research documents, whether they are published or not. The documents may come from teaching and research institutions in France or abroad, or from public or private research centers.
L'archive ouverte pluridisciplinaire $\mathbf{H A L}$, est destinée au dépôt et à la diffusion de documents scientifiques de niveau recherche, publiés ou non, émanant des établissements d'enseignement et de recherche français ou étrangers, des laboratoires publics ou privés. 


\title{
Theoretical Investigation of Phosphinidene Oxide Polypyri- dine Ruthenium(II) Complexes: Towards the Design of a New Class of Photochromic Compounds
}

\author{
Olivier P. J. Vieuxmaire, ${ }^{\dagger}$ Rémi E. Piau, ${ }^{\dagger}$ Fabienne Alary, ${ }^{\dagger}$ Jean-Louis Heully, ${ }^{\dagger}$ Pierre Sutra, ${ }^{\ddagger, \S}$ Alain \\ Igau, ${ }^{*}, \AA$ Martial Boggio-Pasqua ${ }^{*}+$
}

\author{
'Laboratoire de Chimie et Physique Quantiques - IRSAMC, CNRS et Université de Toulouse, 118 route de Nar- \\ bonne, 31062 Toulouse Cedex 09, France \\ ‡LCC (Laboratoire de Chimie de Coordination), CNRS, 205 route de Narbonne, F-31077 Toulouse, France \\ \&UPS, INPT, LCC, Université de Toulouse, F-31062 Toulouse, France
}

\begin{abstract}
DFT-based computational study performed in the gas phase and in acetonitrile on polypyridine ruthenium isomer complexes $[\mathrm{Ru}(\mathrm{tpy})(\mathrm{bpy})(\mathrm{POPh})]^{2+}$ and $[\mathrm{Ru}(\mathrm{tpy})(\mathrm{bpy})(\mathrm{OPPh})]^{2+}\left(\mathrm{bpy}=2,2^{\prime}\right.$-bipyridine, tpy = 2,2':6',2'"-terpyridine, $\mathrm{Ph}=$ phenyl) predicts that it constitutes a prototype for a new family of inorganic photochromic systems. The two isomers are found to absorb in different spectral regions to excited states that are connected adiabatically through a thermodynamically and kinetically favorable triplet potential energy profile. Nonadiabatic routes were identified and shown to be preferable over the adiabatic mechanism. The reverse isomerization reaction is found to be achievable only thermally. The current predictive work will be of prime importance to experimentalists for the design of new inorganic phosphorus-based compounds with attractive photochromic properties.
\end{abstract}

KEYWORDS: Computational Chemistry $\bullet$ Photochemistry $\bullet$ Density Functional Theory $\bullet$ Excited States $\bullet$ Nonadiabatic Transitions

Throughout the years, the development of new molecular systems that display photoisomerization or photochromism has become an increasing area of research. These structures have entered the new generation of innovative functional materials with high added value. Applications are already widespread in nanosciences, biology and photonic or optoelectronic devices as light-activated switches. ${ }^{1,2,3,45,6,7,8}$ Studies in those domains have for a long time been dominated by organic structures ${ }^{3-8}$ comparatively to transition metal compounds ${ }^{9,10,11,12,13,14,15,16}$ even though these latter offer a large range of flexibility in the tuning of photochemical and photophysical properties.

Photoinduced linkage isomerism involving polypyridine ruthenium complexes has so far been described with ambidentate ligands through the coordination of $\mathrm{N}, \mathrm{O}$, and $S$ atoms. ${ }^{13,14,17,18,19,20,21,22,23}$ Phosphorus compounds are among the most frequently used ligands in transition metal chemistry for catalysis applications. ${ }^{24}$ It is noteworthy that to date phosphorus atom has not yet been involved in a linkage isomerism process despite the large variety of available organophosphorus derivatives.

In a continuing effort to probe the photophysical and photochemical properties of polypyridine ruthenium(II) complexes incorporating phosphorus ligands with the phosphorus atom directly connected to the metal center, ${ }^{25,26,27,28,29}$ we intended to start a theoretical investigations on the capability of organophosphorus compounds to act as ambidentate ligands for linkage isomerism. Within the chemistry of organophosphorus compounds, one class of substances which could fulfill the criteria to observe linkage isomerism are phosphinidene oxides $\mathrm{R}-\mathrm{P}=\mathrm{O}$. In contrast to their nitrogen analogues $\mathrm{R}-\mathrm{N}=\mathrm{O}$ which are isolable and commercially available species, phosphinidene oxides $\mathrm{R}-\mathrm{P}=\mathrm{O}$ are unstable compounds; their stabilization is achieved through the coordination to metal centers. Phosphinidene oxide ligands display a rich variety of coordination modes on $\mathrm{P}$ and $\mathrm{O}$ atoms, and $\mathrm{P}$ terminal coordination mode has been confirmed by singlecrystal X-ray diffraction studies. ${ }^{30,31,32,33,34,35}$ Though, these ambidentate organophosphorus derivatives may be considered as good prototype species for linkage isomerism process. Possible modulation of the ligand by substitution of the $\mathrm{R}$ group is also an important asset.

The object of the current article is the computational investigation of a new class of transition metal compounds, which involves polypyridine ruthenium complexes containing a phosphinidene oxide ligand. The model photoisomers studied here are $[R u(t p y)(b p y)(P O P h)]^{2+}$ and $\left[R u(t p y)(\text { bpy) }(\mathrm{OPPh})]^{2+}\right.$ (where bpy $=2,2$ '-bipyridine, tpy = $2,2^{\prime}: 6^{\prime}, 2^{\prime \prime}$-terpyridine and $\mathrm{Ph}=$ phenyl), shown in Figures 1a-c. We will use the notation RuP and RuO to refer to any $P$-bonded and $\mathrm{O}$-bonded species, respectively. The most reliable method allowing one to map out the potential energy surfaces in such large systems is the density func- 
tional theory (DFT). ${ }^{36,37,38,39}$ In particular, such a method was recently used to shed some light on the photoisomerization mechanism in a ruthenium sulfoxide complex. ${ }^{37}$ Based on this successful mechanistic study, a similar approach has been followed in this work to predict for the first time the isomerizable capability of a $\mathrm{Ru}-\mathrm{P}=\mathrm{O}$ complex.

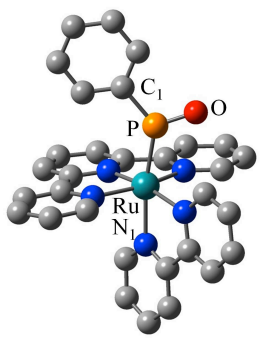

(a)

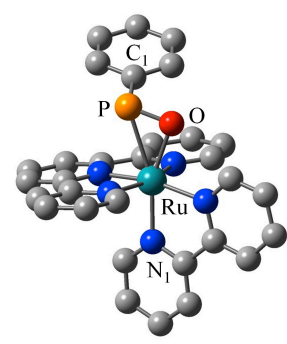

(b)

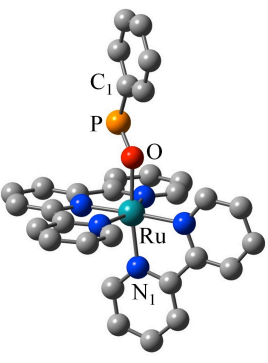

(c)
Figure 1. Geometrical structures of the gas-phase optimized (a) P-GS, (b) PO-GS and (c) O-GS minima in the ground state.

The main result of our study is that the RuP complex can photoisomerize to RuO: both isomers are found to absorb in different spectral regions to excited states that are connected together through a thermodynamically and kinetically favorable potential energy profile. In this profile displayed in Figure 2, the RuP ground state (denoted P-GS) is predicted to absorb in the ultra-violet (UV) to a singlet excited state that decays to a triplet excited state via spinorbit coupling. The photoreaction then takes place on the triplet potential energy surface (PES). The isomerization process that yields the RuO ground state (denoted O-GS) can occur either adiabatically or non-adiabatically through funnels lying along the adiabatic pathway.

The article is organized as follows. Following the description of the computational methods, the photochromic mechanism computed in the gas phase and in solvent as well as the probability of the system to decay nonadiabatically along the path are described and discussed. In the final part, a summary of the predictive results is given with future outlooks.

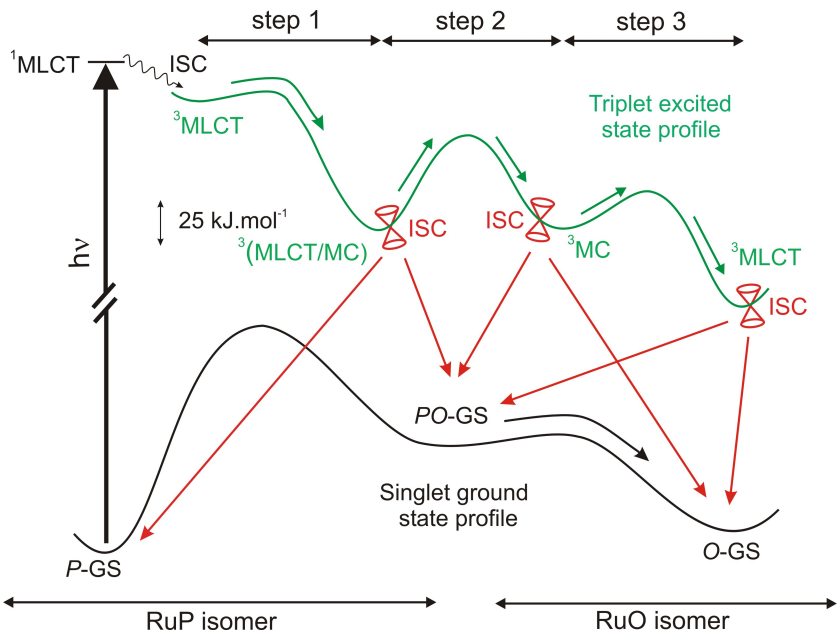

Figure 2. Schematic representation of the adiabatic (green line) and nonadiabatic (red line) mechanisms of the RuP $\rightarrow$ RuO photoisomerization process (MLCT: metal-to-ligand charge transfer; MC: metal-centered; ISC: intersystem crossing). Triplet/singlet funnels are represented by double cone pictograms.

\section{COMPUTATIONAL METHODS}

DFT calculations were performed using the Gaussian 09 suite of quantum chemistry programs. ${ }^{40}$ The MPWB1K functional ${ }^{41}$ was selected based on the results of a number of benchmark calculations performed in previous studies for polypyridine ruthenium(II) systems. ${ }^{28}$ The calculations were carried out using two different sets of basis denoted BS1 and BS2. BS1 is a fairly small basis set, which was first used for exploratory calculations. It is composed of a double- $\zeta$ quality LANL2DZ basis $\operatorname{set}^{42,43}$ for all atoms but oxygen and phosphorus which were described by the 6 $31 \mathrm{G}(\mathrm{d})$ split valence Pople basis. ${ }^{44,45,46}$ The much larger basis set BS2 was used for production results. It is made of a Stuttgart relativistic small-core effective potential for ruthenium ${ }^{47}$ with its basis augmented by an $f$ polarization function with an exponent of 0.96, a triple- $\xi$ plus polarization basis set $^{48}$ for all the other atoms but hydrogen for which a double- $\zeta$ plus polarization basis set ${ }^{48}$ was used.

The ground state structures $P$-GS and O-GS were optimized using the BS2 basis set. The 5.9 version of the natural bond orbital (NBO) program ${ }^{49}$ has been used for the description of the bonding for the RuP isomer in the gas phase. Time-dependent DFT (TD-DFT) calculations were performed at the optimized ground state geometry of each isomer using the PBE0 functional, ${ }^{50}$ as MPWB1K is an heavily parameterized functional not optimized for TDDFT calculations. The first thirty singlet roots were computed in each case in order to obtain the main vertical excitation energies and the overall absorption spectrum of both isomers. The nature of the excited states giving rise to the UV/vis spectrum was analyzed using the NTO formalism. . $^{51,52,53,54}$

The complete triplet PES over which the photoisomerization process takes place was constructed by optimizing all the minima and transition states using an unrestricted formalism. Analytical harmonic vibrational frequency calculations were performed to characterize the nature (minimum vs. transition state) of the stationary points found on this PES and to obtain the enthalpic and entropic corrections necessary to calculate the Gibbs energies. All the energies indicated and discussed in the subsequent sections are Gibbs energies calculated at $298 \mathrm{~K}$ unless otherwise specified. Mulliken spin density on the ruthenium atom was computed in order to highlight the metal-toligand charge transfer (MLCT: $1 \mathrm{e}^{-}$) or metal centered (MC: $\sim 2 \mathrm{e}^{-}$) character. Note that we are confident that DFT can describe the relative energy of MLCT and MC states based on a recent benchmark study. ${ }^{55}$ Spin contamination was found to be negligible in all cases. Natural molecular orbitals were also computed for all the minima optimized along the potential energy profiles (orbitals shown in Tables S1 to S15).

In order to build the complete potential energy profile, intrinsic reaction coordinate (IRC) calculations, which pro- 
vide an accurate description of the reaction pathway, were performed from the optimized transition structures to connect all the stationary points. Because of the very high computational demand to perform such calculations, the smaller BS1 basis set was used.

$\Delta$-SCF calculations, which yield the energy difference between the triplet excited states at their optimized geometries and the closed-shell ground state at the same geometry, were performed along the photoisomerization path to indicate the proximity of the lowest triplet excited state energy profile to the ground state energy surface. In order to find nonadiabatic routes along the photoisomerization pathway, minimum energy crossing points (MECPs) were searched between the ground and lowest triplet states. These MECPs were fully optimized using the ORCA computational suite. ${ }^{56}$ Because the MPWB1K functional is not available in this package, the PBEO functional including the VDW10 dispersion correction ${ }^{57}$ was used along with the BS2 basis set. To assess possible groundstate relaxation pathways from these MECPs, we performed linearly interpolated transit paths between these MECPs and the ground-state minima (Figures S1-S3).

Geometry optimization calculations have also been done using the polarized continuum model $(\mathrm{PCM})^{58}$ so as to evaluate the effects of solvation upon the photoisomerization pathway. The acetonitrile solvent was chosen because of the intermediate value (35.7) of its dielectric constant and its wide use with this kind of complexes.

Note that our DFT calculations do not take spin-orbit effects into account. Spin-orbit coupling leads to the mixing of the singlet and triplet states. As a result, triplet states can acquire intensity in both absorption and emission, and they can be populated from (or depopulated to) singlet states by nonradiative decay (intersystem crossing). Spinorbit coupling also affects the energy of the lowest triplet state upon coupling with higher states. However, the magnitude of the coupling is small enough in this type of complexes (ca. $\left.4 \mathrm{~kJ} \mathrm{~mol}^{-1}\right)^{59}$ that this perturbation will not modify the topology of the PES computed without this coupling. It is therefore a common practice to neglect the SOC in the computation of PES of second row transition metals. ${ }^{36,37,38,60,61,62}$ Although spin-orbit effects are not included in our calculations, we do take into account these effects in deriving the nonadiabatic mechanistic picture presented in section IV.

\section{RESULTS \& DISCUSSION}

I. Ground-state energy profile. The ground-state energy profiles computed in the gas phase and acetonitrile are shown in Figures $3 a$ and $3 b$, respectively. These profiles connect $P$-GS to $O$-GS via the $\eta^{2} P O-G S$ intermediate. The optimized structures and the topology of the energy profile are found overall to be very similar in both the gas phase and acetonitrile. Details of all the molecular and electronic structures are given in Table 1 and in Supporting Information (Tables S1-S5). Although the geometrical parameters and the results of the $\mathrm{MO}$ analysis report- ed here are from the structures optimized in the gas phase, the subsequent discussion and conclusions drawn from them are equally valid for the solvated phase case.

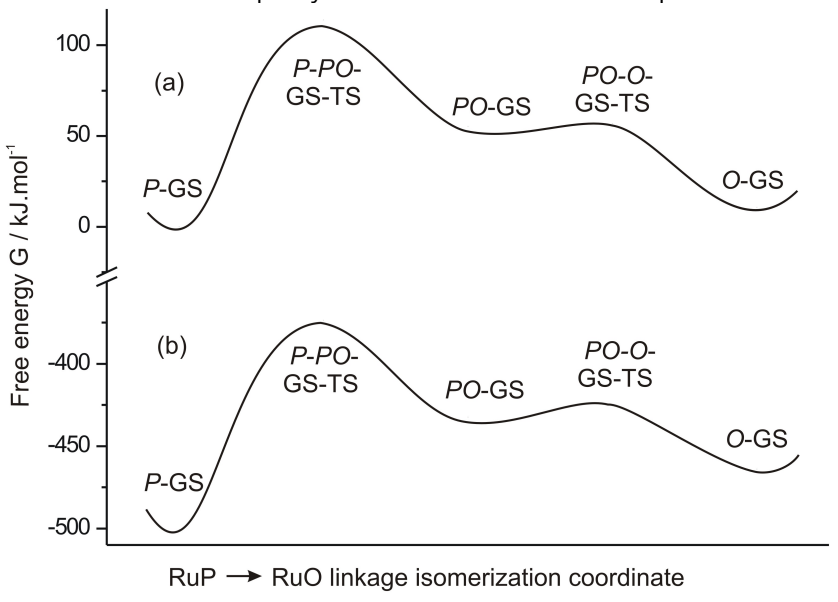

Figure 3. Singlet ground-state free energy profile of the RuP $\rightarrow \mathrm{RuO}$ isomerization process (a) in the gas phase and (b) in acetonitrile.

The optimized structures of both RuP and RuO complexes in their ground state are displayed in Figures 1a and 1c. In the RuP isomer, the highest occupied molecular orbital (HOMO) consists of a Ru(4d) orbital, while the lowest unoccupied molecular orbital (LUMO) is distributed mostly between the tpy ligand and the $\mathrm{P}$ and $\mathrm{O}$ atoms of the phosphinidene oxide POPh ligand (Table S1). Experimental values of Ru-P bond lengths observed in other $\mathrm{Ru}-$ $P$ complexes were found to range from $2.159 \AA^{63}$ to 2.428 $\AA .{ }^{64}$ The short value of this bond length obtained from our calculations (2.229 $\AA$, Table 1) tends to indicate non-single bonding character. The NBO analysis did not reveal a $\pi$ bond between the Ru and $\mathrm{P}$ centers, but only weak back donation from Ru to P (Figure 4). This bond length is also consistent with other values which can be found in $\mathrm{Fe}-$ $(2.091 \AA),{ }^{33} \operatorname{Re}-(2.203 \AA)^{31}$ and Mo- $(2.239-2.319 \AA)^{32,34,35}$ phosphinidene oxide complexes. It is also worth noting that the $\mathrm{C}-\mathrm{P}-\mathrm{O}-\mathrm{Ru}$ backbone is planar (the corresponding dihedral angle is $-178.1^{\circ}$ ).

The NBO analysis reveals that the $\mathrm{P}-\mathrm{O}$ bond is strongly polarized in the ground state of each species. The charge from the natural population analysis (NPA) of the $O$ atom, -0.97 , remains surprisingly constant in both isomers, whereas the charge on $\mathrm{P}$ changes from 1.62 in $P$-GS to

Table 1. Main geometrical parameters of the gas-phase optimized structures on the GS potential energy surface (bond lengths in $\AA$ and dihedral angles in ${ }^{\circ}$ ).

\begin{tabular}{llllll}
\hline $\begin{array}{l}\text { Geometrical } \\
\text { parameters }\end{array}$ & $P$-GS & $\begin{array}{l}P \text {-PO- } \\
\text { GS-TS }\end{array}$ & $\begin{array}{l}P O- \\
\text { GS }\end{array}$ & $\begin{array}{l}\text { PO-O- } \\
\text { GS-TS }\end{array}$ & O-GS \\
\hline Ru-P & 2.229 & 2.659 & 2.576 & 2.868 & 3.303 \\
Ru- $N_{1}$ & 2.123 & 2.023 & 2.070 & 2.042 & 2.040 \\
Ru-O & 3.217 & 2.824 & 2.136 & 2.178 & 2.100 \\
P-O & 1.485 & 1.501 & 1.544 & 1.529 & 1.525 \\
C - - $-O-R u$ & -178.1 & -124.0 & -101.6 & 114.1 & 179.7 \\
\hline
\end{tabular}


1.32 in $\mathrm{O}-\mathrm{GS}$. The charge on $\mathrm{Ru}$ is found to increase roughly by the same amount (Table S16). This is consistent with the strong difference of electronegativity between the $\mathrm{P}$ and $\mathrm{O}$ elements and the change in bond linkage between the two complexes. In P-GS, the terminal $O$ is only bound to the phosphorus atom resulting in strong electronic withdrawal on $\mathrm{P}$ alone, while the $\mathrm{O}$ atom in O-GS is coordinated to both the metal center and P. In the latter configuration, the charge depletion caused by the electronegative $\mathrm{O}$ atom is more equally shared between the $\mathrm{P}$ and $\mathrm{Ru}$ atoms.

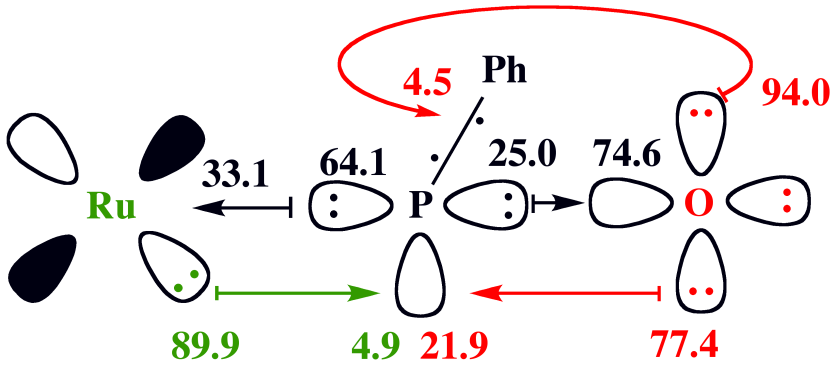

Figure 4. Description of the Ru-P and $\mathrm{P}-\mathrm{O}$ bonds based on natural localized molecular orbital (NLMO) analysis in the ground state of the RuP isomer. The arrows represent the direction of the electron transfer. Each number represents the electron percentage left on the donor (start of the arrow) or transferred from the donor to the acceptor (end of the arrow).

The nature of the $\mathrm{P}-\mathrm{O}$ bond has been widely studied and discussed for different organophosphorus derivatives such as phosphine oxide, ${ }^{65,66,67,68}$ diphenylphosphonic acid ${ }^{69}$ and phosphates. ${ }^{70}$ Several approaches using theoretical methods $^{66,69,71}$ (NBO analysis, electron localization function analysis) as well as spectroscopy (X-ray diffraction, IR) $)^{69,72}$ did not end the controversy. In a very recent work, Koga et al. recalled the main models used to describe the $\mathrm{P}-\mathrm{O}$ bond (Chart 1 in Ref. 65).

In P-GS, the bond length of the $\mathrm{P}-\mathrm{O}$ bond is equal to $1.485 \AA$. This length is consistent with usual values obtained for formally double P-O bonds in other systems. ${ }^{69,71}$ Using NBO analysis (Figure 4), and on the basis of natural localized molecular orbital involving the oxygen, phosphorus and ruthenium atoms, the multiple bond character of $\mathrm{P}-\mathrm{O}$ in the POPh ligand can be depicted with dative interactions: one $\sigma$ dative bond where the $P$ atom is clearly electron donor and one $\pi$ dative bond where the phosphorus atom is the electron acceptor. Hyperconjugation of an $\mathrm{O} p$ lone pair (4.5\% of two electrons) with $\mathrm{P}-\mathrm{Ph}$ antibonding orbitals slightly contributes to the reinforcement of this double bond, while its last lone pair does not play an active role in the bonding scheme. As shown by the NPA given above, the ionic character of the $\mathrm{P}-\mathrm{O}$ bond $\left(\mathrm{P}^{\delta+}-\mathrm{O}^{\delta-}\right)$ results of a charge transfer of ca. $75 \%$ from the $P$ atom toward the $\mathrm{O}$ atom.

The O-GS optimized structure is only $10.7 \mathrm{~kJ} \mathrm{~mol}^{-1}$ higher in energy than the $P$-GS state optimized in the gas phase

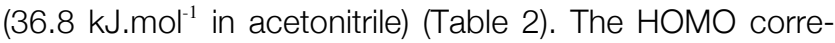
sponds to a Ru(4d) orbital, whereas the LUMO involves uniquely the $\mathrm{P}$ and $\mathrm{O}$ atoms and the phenyl group of the $\mathrm{OPPh}$ ligand. The value of the $\mathrm{C}_{1}-\mathrm{P}-\mathrm{O}-\mathrm{Ru}$ dihedral angle, calculated at $179.7^{\circ}$, indicates that the new bond linkage preserves the backbone planarity.

Table 2. Energies and Gibbs energies at $298 \mathrm{~K}$ of the optimized structures associated to the states involved in the GS energy profile (energies in $\mathrm{kJ} \cdot \mathrm{mol}^{-1}$ ).

\begin{tabular}{llll}
\hline Structures & $\Delta \mathrm{E}^{a}$ & $\Delta \mathrm{G}^{b}$ & $\Delta \mathrm{G}^{c}$ \\
\hline P-GS & 0 & 0 & 0 \\
P-PO-GS-TS & 119.1 & 114.0 & 127.1 \\
PO-GS & 51.7 & 55.3 & 68.3 \\
PO-O-GS-TS & 57.3 & 56.6 & 75.5 \\
O-GS & 18.1 & 10.7 & 36.8 \\
\hline
\end{tabular}

${ }^{a}$ Gas phase energies relative to $P$-GS. ${ }^{b}$ Gas phase Gibbs energies relative to $P$-GS. ${ }^{c}$ Gibbs energies in acetonitrile relative to $P$-GS.

The optimized intermediate (PO-GS) that joins both $P$-GS and $O-G S$ species is displayed in Figure $1 \mathrm{~b}$. This structure is a minimum and lies 55.3 and $44.6 \mathrm{~kJ}^{-\mathrm{mol}^{-1}}$ higher in energy relative to the $P$-GS and $O$-GS minima respectively

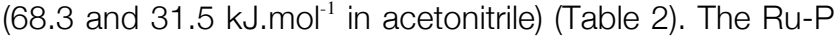
and $\mathrm{Ru}-\mathrm{O}$ bond lengths are relatively close and a near side-on configuration of the $\mathrm{P}-\mathrm{O}$ moiety is observed. The existence of intermediate $\eta^{2}$-structure minima has been reported experimentally in several photoisomerizable systems, at least at low temperatures. ${ }^{23,73,74,75,76}$

The $P O-G S$ is found to be connected to the $P$-GS and $O$ GS isomers through the optimized transition states $P$-POGS-TS and PO-O-GS-TS displayed in Figures S4a,b (see also IRC in Figure S5). The transition vectors (vibrational normal mode corresponding to the unique imaginary frequency) can be viewed mainly as a scissoring vibration $\mathrm{Ru}-\mathrm{P}-\mathrm{O}$ in $\mathrm{P}-\mathrm{PO}-\mathrm{GS}-\mathrm{TS}$ and a scissoring vibration $\mathrm{Ru}-\mathrm{O}-\mathrm{P}$ in PO-O-GS-TS, so that the $\mathrm{O}$ atom gets closer to the $\mathrm{Ru}$ center while the $P$ atom gets further away. An activation barrier of $58.7 \mathrm{~kJ} \mathrm{~mol}^{-1}$ and only $1.3 \mathrm{~kJ} \mathrm{~mol}^{-1}$ in the gas

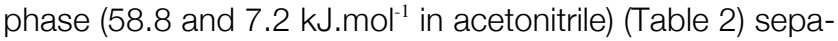
rates $P O-G S$ from $P$-GS and $O-G S$ respectively. At room temperature, O-GS is expected to be directly reached from $P O-G S$.

Despite being relatively close in energy in the gas phase, $P$-GS and O-GS are separated overall by a large barrier, calculated at $114 \mathrm{~kJ} \mathrm{~mol}^{-1}\left(127.1 \mathrm{~kJ} \mathrm{~mol}^{-1}\right.$ in acetonitrile), which indicates that both species will be kinetically well separated. Such bistability is an important property in the design of efficient photochromic systems.

II. Absorption properties. The computed TD-DFT absorption spectra of $P$-GS and O-GS are displayed in Figure 5. The details of the electronic transitions contributing to the spectra are given in Figures S8-S9 and Tables S17-S18.

In the RuP spectrum, the strongest absorption band computed in the $270-310 \mathrm{~nm}$ region consists of intra-ligand and ligand-ligand transitions. The peak centered at 366 $\mathrm{nm}$ corresponds mostly to a MLCT transition from a $\mathrm{Ru}(4 \mathrm{~d})$ orbital to a MO distributed on the POPh ligand. The 
latter transition corresponds in fact to the electronic promotion from the HOMO to the LUMO identified for $P$-GS in acetonitrile. Most of the computed transitions lie unusually below $400 \mathrm{~nm}$ and as such the RuP compound is expected to be transparent.

The overall envelope of the RuO TD-DFT spectrum consists of three bands. The strongest absorption line at 552 $\mathrm{nm}$ corresponds to the excitation from a $\mathrm{Ru}(4 \mathrm{~d})$ orbital to the OPPh ligand. The other two absorption lines which are of similar strength consist of excitations from the $\mathrm{Ru}(4 \mathrm{~d})$ orbitals to MOs distributed between the tpy and the bpy ligands. Similarly to RuP, the absorption line of lowest energy is identified as the LUMO $\leftarrow \mathrm{HOMO}$ transition. As $\mathrm{RuO}$ is found to absorb mostly in the visible range, the $\mathrm{RuO}$ isomer should be colored.

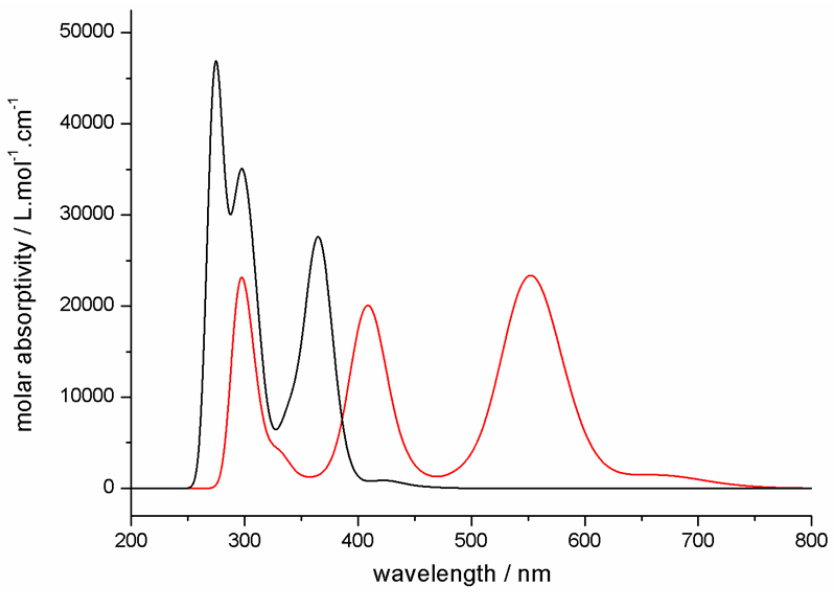

Figure 5. Computed absorption spectra for the ground state of the RuP (black curve) and RuO (red curve) isomers in acetonitrile. Broadening function used: Gaussian with a halfwidth at half-height of $0.1 \mathrm{eV}$.

The TD-DFT results show that an essential condition for a system to be photochromic is fulfilled: the two species absorb in two different regions of the spectrum and therefore will display different colors. It is then expected that a visible change in colors will occur upon RuP $\rightarrow \mathrm{RuO}$ isomerization whose mechanism is presented in the next sections.

III. Adiabatic photoisomerization pathway. Due to singlet-triplet mixing induced by the spin-orbit coupling in transition metal compounds, the quantum efficiency for intersystem crossing is expected to be close to unity. ${ }^{77}$ Therefore, initial excitation to a singlet MLCT state, such as in the strong transition computed at $366 \mathrm{~nm}$ in the RuP TD-DFT spectrum, will lead to population of a triplet MLCT via intersystem crossing. Thus we only consider the adiabatic mechanism on the lowest triplet PES. This mechanism computed in the gas phase and in acetonitrile (Figure 6) can be divided into three successive steps. Each step is described in the following subsections. Details of all the molecular and electronic structures of the located stationary points are given in Table 3 and in Supporting Infor- mation (Tables S6-S13). We will show that various MLCT and $\mathrm{MC}$ states are involved along the process.

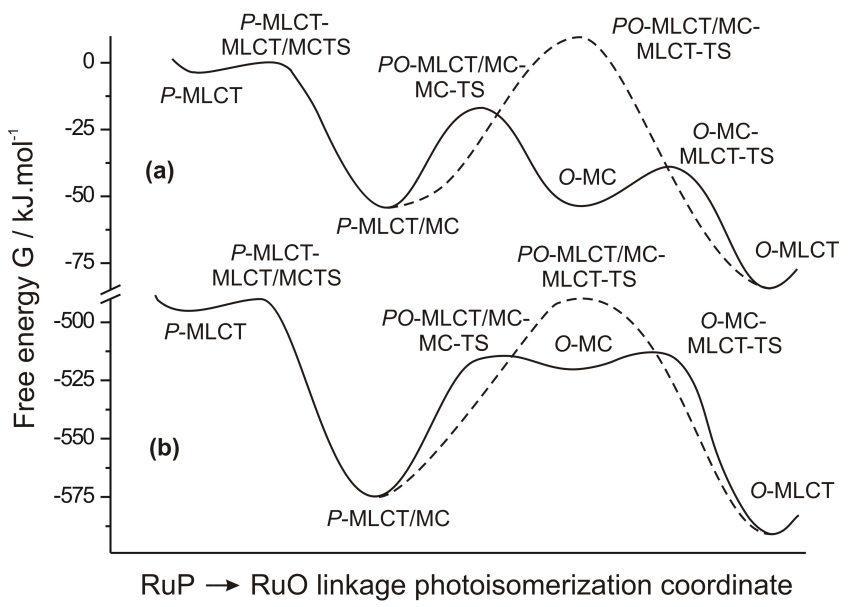

Figure 6. Lowest triplet excited-state free energy profile along the photoisomerization process (a) in the gas phase and (b) in acetonitrile computed at the MPWB1K/BS2 level. Full line: lowest isomerization pathway; dashed line: alternative isomerization step of higher energy.

$1^{\text {st }}$ step $P$-MLCT $\rightarrow P$-MLCT/MC. The first stage of the predicted photoisomerization process consists of the pathway between an MLCT state (denoted $P$-MLCT) and a mixed MLCT/MC state (denoted P-MLCT/MC) on the $P$ bonded part of the PES.

In the P-MLCT state, the singly occupied molecular orbital of lowest energy (SOMO) corresponds mostly to one $4 \mathrm{~d}$ orbital of the metal center. The SOMO of highest energy $(\mathrm{SOMO}+1)$ is localized on the tpy ligand. The geometrical structures of $P$-MLCT and $P$-GS are very similar. The most noticeable difference between them is the change of length in the $\mathrm{C}-\mathrm{C}$ bond connecting two of the three pyridine rings in the tpy moiety, which is due to the electronic transfer toward a $\pi^{\star}$-tpy orbital. The value of 0.93 for the spin density (0.94 in acetonitrile) is in accord with the description of the SOMOs.

The optimized transition structure between P-MLCT and P-MLCT/MC features a Ru-P bond length of $2.309 \AA$ and a $\mathrm{C}_{1}-\mathrm{P}-\mathrm{O}-\mathrm{Ru}$ dihedral angle of $-165.9^{\circ}$ in the gas phase (Table 3) (2.271 $\AA$ and $-176.3^{\circ}$ in acetonitrile). These two values are close to the corresponding values of the $P$ MLCT minimum. The transition vector (Figure S4c) involves mostly the breaking of the $\mathrm{C}_{1}-\mathrm{P}-\mathrm{O}-\mathrm{Ru}$ plane along with a modest stretching of the Ru-P and P-O bonds. An IRC calculation started from this structure denoted P-MLCTMLCT/MC-TS (Table S7 and Figure S6a) confirms that it connects the P-MLCT and P-MLCT/MC states. The resemblance of the TS and P-MLCT structures is reflected in the very close energies between these two states, which results in a negligible activation barrier (Table 4). Thus, the $P$-MLCT/MC state will be rapidly reached upon relaxation from the initially excited singlet MLCT state. 
Table 3. Main geometrical parameters of the gas-phase optimized structures on the triplet potential energy surface (bond lengths in $\AA$ and dihedral angles in ${ }^{\circ}$.

\begin{tabular}{lllllllll}
\hline $\begin{array}{l}\text { Geometrical } \\
\text { parameters }\end{array}$ & $P$-MLCT & $\begin{array}{l}P-M L C T- \\
\text { TS }\end{array}$ & $\begin{array}{l}P \text {-MLCT } \\
\text { /MC }\end{array}$ & $\begin{array}{l}\text { PO- } \\
\text { MLCT- } \\
\text { MC-TS }\end{array}$ & $\begin{array}{l}\text { PO- } \\
\text { MLCT-TS }\end{array}$ & O-MC & $\begin{array}{l}\text { O-MC- } \\
\text { MLCT-TS }\end{array}$ & O-MLCT \\
\hline Ru-P & 2.273 & 2.309 & 2.402 & 3.102 & 2.508 & 3.748 & 3.483 & 3.239 \\
Ru-N & 2.125 & 2.106 & 2.178 & 2.241 & 2.041 & 2.356 & 2.279 & 2.085 \\
Ru-O & 3.244 & 3.261 & 3.228 & 2.954 & 2.312 & 2.525 & 2.218 & 1.924 \\
P-O & 1.481 & 1.486 & 1.511 & 1.504 & 1.562 & 1.512 & 1.536 & 1.634 \\
C 1 -P-O-Ru & -177.7 & -165.9 & -122.7 & -104.8 & -148.5 & -167.6 & -109.1 & -104.1 \\
\hline
\end{tabular}

Table 4. Energies and Gibbs energies at $298 \mathrm{~K}$ of the optimized structures associated to the states involved in the triplet excited energy profile (energies in $\mathrm{kJ} \cdot \mathrm{mol}^{-1}$ ).

\begin{tabular}{llll}
\hline Structures & $\Delta \mathrm{E}^{a}$ & $\Delta \mathrm{G}^{b}$ & $\Delta \mathrm{G}^{c}$ \\
\hline P-MLCT & 0 & 0 & 0 \\
P-MLCT-MLCT/MC-TS & 2.9 & 0.8 & 0 \\
P-MLCT/MC & -62.7 & -52.1 & -77.7 \\
PO-MLCT/MC-MC-TS & -14.1 & -13.7 & -20.7 \\
PO-MLCT/MC-MLCT-TS & 1.4 & 8.1 & -1.6 \\
O-MC & -37.6 & -51.8 & -21.1 \\
O-MC-MLCT-TS & -30.5 & -36.7 & -19.0 \\
O-MLCT & -91.8 & -83.4 & -95.7 \\
\hline
\end{tabular}

${ }^{a}$ Gas phase energies relative to $P$-MLCT. ${ }^{b}$ Gas phase Gibbs energies relative to $P$-MLCT. ${ }^{c}$ Gibbs energies in acetonitrile relative to $P$-MLCT.

For the $P$-MLCT/MC state, the SOMO corresponds to the same $\mathrm{Ru}(4 \mathrm{~d})$ orbital than in the P-MLCT state. The $\mathrm{SOMO}+1$ is mostly distributed between the $\mathrm{P}$ and $\mathrm{O}$ atoms (and to a less extent the phenyl ring) on the one hand and a $\mathrm{d} \sigma^{*}$ orbital on the other hand (Table S8). The value of 1.20 for the spin density on $\mathrm{Ru}$ (1.14 in acetonitrile), which is atypical either of a MLCT state or a MC state, reflects the particular mixed configuration of the SOMO+1. The main reason for the increase of the Ru-P, and to a less extent of the Ru- $\mathrm{N}_{1}$, bond lengths relative to $P$-MLCT is the electronic excitation to a $\mathrm{d} \sigma^{\star}$ orbital (MC character), which induces the partial decoordination of the ligands along the Ru-P axis. The breaking of the $\mathrm{C}_{1}-\mathrm{P}-\mathrm{O}-\mathrm{Ru}$ planarity (measured at $-122.7^{\circ}$ in the gas phase) is due to electronic excitation to POPh (MLCT character). It is also important to note that the P-MLCT/MC state is much lower in energy $\left(-52 \mathrm{~kJ} \mathrm{~mol}^{-1}\right.$ in the gas phase and -78 $\mathrm{kJ} \mathrm{mol}^{-1}$ in acetonitrile, Table 4) than P-MLCT, thus this step is highly favorable both kinetically and thermodynamically.

It is worth noting that a P-MC state that involves decoordination of the tpy ligand has been identified at higher energy $\left(12 \mathrm{~kJ} \cdot \mathrm{mol}^{-1}\right)$ relative to $P$-MLCT/MC and does not play a direct role in the photoisomerization because the reaction coordinate producing this $\mathrm{MC}$ state does not involve linkage isomerization (Figure S10, Tables S14, S19).

$2^{\text {nd }}$ step $P$-MLCT/MC $\rightarrow O-M C$. The second step in the isomerization pathway involves the actual change in the chain linkage between the two isomers. This occurs between the previously discussed P-MLCT/MC state of RuP and the O-MC state.

A transition state, denoted PO-MLCT/MC-MC-TS, with a side-on configuration of the $\mathrm{PO}$ moiety connects the $P$ MLCT/MC and O-MC states. The Ru-P and Ru-O bond distances are close to each other, $3.102 \AA$ and $2.954 \AA$, respectively in the gas phase. The $\mathrm{SOMO}+1$ involves an antibonding interaction between the metal center with the $\mathrm{P}$ and $\mathrm{O}$ atoms, indicating a $\eta^{2}$ coordination mode. The transition vector mostly consists of a scissoring Ru-P-O (Figure S4d), in which the $\mathrm{O}$ atom gets closer to the metal center as the $\mathrm{P}$ atom gets further away. This step corresponds to the linkage isomerization step. An IRC calculation started from this transition state structure (Figure S6b) confirms that it connects the P-MLCT/MC and O-MC states. The $P$-MLCT/MC $\rightarrow O-M C$ activation barrier computed at $38 \mathrm{~kJ} \cdot \mathrm{mol}^{-1}$ in the gas phase $\left(57 \mathrm{~kJ} \cdot \mathrm{mol}^{-1}\right.$ in acetonitrile, Table 4) is the largest of all the barrier heights calculated in the predicted isomerization pathway. This second stage is thus kinetically the critical step of the whole RuP to RuO adiabatic photoisomerization process.

The O-MC state results from the promotion of an electron from a $\mathrm{Ru}(4 \mathrm{~d})$ orbital to a $\mathrm{d} \sigma^{\star}$ orbital. As a consequence, the Ru-O and Ru-N bond lengths, 2.525 and $2.356 \AA$ respectively (Table 3) (2.630 and $2.322 \AA$ in acetonitrile, Table S21), are increased in comparison with their respective values in O-GS (Table 1). The O-MC state in the gas phase is found to be very close in energy to the $P$ MLCT/MC state of the $P$-bonded isomer, but higher in energy in acetonitrile (Table 4).

It is worth noting that a second $\mathrm{O}-\mathrm{MC}$ state (denoted $\mathrm{O}$ $\mathrm{MC}_{2}$ ) involving decoordination of the tpy ligand was located at higher energy ( $5 \mathrm{~kJ} \mathrm{~mol}^{-1}$ ) relative to $\mathrm{O}-\mathrm{MC}$ and, like for the $P$-MC state, does not play a direct role in the photoisomerization (Figure S10, Tables S15, S19). 
$3^{\text {rd }}$ step O-MC $\rightarrow$ O-MLCT. The third and final stage of the adiabatic isomerization mechanism connects the previously described O-MC state to the O-MLCT state.

A transition state, denoted O-MC-MLCT-TS, connects the $\mathrm{O}-\mathrm{MC}$ and O-MLCT states. The transition vector consists to a large extent of the stretching of the Ru-O and Ru-N bonds (Figure S4f). The IRC calculation (Figure S7b) confirms the connection between these states. The activation barrier of this third step is calculated at $15 \mathrm{~kJ} \mathrm{~mol}^{-1}$ in the gas phase $\left(2 \mathrm{~kJ} \mathrm{~mol}^{-1}\right.$ in acetonitrile, Table 4$)$, which is less than half the value of the critical barrier height calculated previously in the second step.

In the O-MLCT state, the SOMO involves the same Ru(4d) orbital as in the O-MC state, whereas the SOMO+1 is localized mostly on the phosphinidene oxide OPPh ligand. The major structural differences between $O-G S$ and $O$ MLCT are (Table 1): (i) the change in the dihedral angle $C$ P-O-Ru from $179.7^{\circ}$ to $104.1^{\circ}$, (ii) the decrease of the RuO bond length from 2.100 to $1.924 \AA$ and, (iii) the increase of the P-O distance from 1.525 to $1.634 \AA$. All these geometric changes reflect the nature of the $\mathrm{SOMO}+1$ : excitation on the OPPh ligand (like in the P-MLCT/MC state), bonding character between $\mathrm{Ru}$ and $\mathrm{O}$, and antibonding character between $\mathrm{O}$ and $\mathrm{P}$.

It is worth noting that there exists a O-MLCT state for which the charge transfer takes place to the tpy ligand (as it was found for $P$-MLCT) but this state was not located on the lowest triplet adiabatic PES. Thus, we can exclude the involvement of this state in the photoisomerization.

Alternative step $P$-MLCT/MC $\rightarrow$ O-MLCT. Besides the linkage isomerization mechanism described in steps 2 and 3, another pathway was identified (Figure 6, dashed line). It involves another triplet transition state ( $P O$ MLCT/MC-MLCT-TS) showing also a $\eta^{2}$ coordination with Ru-P and Ru-O bond lengths of 2.508 and $2.312 \AA$, respectively (2.532 and $2.333 \AA$ in acetonitrile). The transition vector (Figure S4e) involves a scissoring Ru-P-O like in PO-MLCT/MC-MC-TS but with a higher imaginary frequency (stiffer mode). The IRC calculation shows that it connects the P-MLCT/MC and O-MLCT states (Figure $\mathrm{S} 7 \mathrm{a})$, thus this step also involves a $\mathrm{Ru}-\mathrm{P} \rightarrow \mathrm{Ru}-\mathrm{O}$ linkage isomerization. The Ru-P and $\mathrm{Ru}-\mathrm{O}$ bond distances at this transition state are found to be much shorter than for the transition state optimized previously (PO-MLCT/MC-MCTS). This is a consequence of the MLCT character (ruthenium spin density: 0.547 , Table S10) of this transition state, whereas PO-MLCT/MC-MC-TS has a MC character (ruthenium spin density: 1.781, Table S9). The activation barrier associated with this alternative step was calculated at $60 \mathrm{~kJ} \cdot \mathrm{mol}^{-1}$ in the gas phase (76 kJ.mol${ }^{-1}$ in acetonitrile), which is larger than the barrier height found for step 2. As a consequence, the isomerization pathway involving the PO-MLCT/MC-MC-TS is expected to be kinetically less favorable in both the gas phase and acetonitrile.

IV. Nonadiabatic isomerization photoreaction. Due to spin-orbit coupling, nonadiabatic transitions back to the ground state can occur. These transitions will be particularly efficient at crossing points between the triplet and the ground state PESs. ${ }^{38,59}$. The result of ground-state energy calculations along the triplet pathway is shown in Figure S11. The singlet-triplet energy gap was found to be relatively small in the region of the triplet state having a $\mathrm{MC}$ character. However, there is one noticeable exception: the case of O-MLCT. In our previous studies, ${ }^{37,78,79}$ singlettriplet energy gaps were always found to be large at MLCT states. In our particular case here, this unusually small gap can be explained by the main relaxation coordinate involving the $\mathrm{C}_{1}$-P-O-Ru torsion in O-MLCT (from $180^{\circ}$ to $-104^{\circ}$ ), a distortion that is energy-costly in the $\mathrm{RuO}$ ground state.

In order to localize precisely the singlet/triplet crossing points, MECPs have been searched starting from structures having a small singlet-triplet energy gap. Three MECPs were identified (Table S22) and named P-MECP, $O-\mathrm{MECP}_{1}$ and $O-\mathrm{MECP}_{2}$, corresponding to one $P$-bonded structure and two $\mathrm{O}$-bonded structures, respectively. No MECP geometry with a $\eta^{2}$ coordination was found. Each MECP geometry was found to be very similar to the geometry of the closest minimum (Figure 2). The P-MECP, $\mathrm{O}-\mathrm{MECP}_{1}$ and $\mathrm{O}-\mathrm{MECP}_{2}$ were located at 3.5, 4.5 and 1.0 $\mathrm{kJ} \cdot \mathrm{mol}^{-1}$ above the P-MLCT/MC, O-MC and O-MLCT minima, respectively. Overall, the activation energies to reach the identified MECP funnels are substantially lower than the adiabatic barriers required to overcome the different transition states. As a consequence, these funnels would be more easily accessible than the transition states on the adiabatic pathway.

Along the first step of the photoisomerization process leading to the $P$-MLCT/MC minimum, the system may decay at the nearby P-MECP (Figure 2). The linear transit pathway calculations (Figure S1) show that two pathways are energetically favorable. The first one leads back to $P$ GS (Figure S1a) and thus corresponds to a nonphotoisomerizing path (photostabilizing pathway). The second one leads to PO-GS (Figure S1b), which, as explained before, will produce eventually the O-GS photoproduct. Note that the third channel that yields directly to O-GS (Figure S1c) is unfavorable due to a large activation barrier.

Assuming that some photoexcited complexes will overcome PO-MLCT/MC-MC-TS and complete the second adiabatic step, the system can then either relax back to $P O-G S$ or O-GS via O-MECP (Figures 2 and S2b,c). The channel leading back to $P$-GS is unfavorable (Figure S2a).

We now consider the case where the system proceeds adiabatically to the final stage (step 3). Given the relaxation profiles calculated for $\mathrm{O}_{-} \mathrm{MECP}_{2}$ (Figure S3), nonadiabatic decay from this crossing point appears to be achievable solely to PO-GS and O-GS (Figure 2). In the same way as for O-MLCT, the back formation of the RuP isomer is unfavorable (Figure S3a).

As a summary (Figure 2), following the first adiabatic step, a remarkable feature of the nonadiabatic mechanism is that the RuP isomer can photoisomerize without going through the critical activation barrier of the second step. 
Another important result is that beyond the $\eta^{2} \mathrm{PO}$ MLCT/MC-MC-TS, the system cannot return to the initial $P$-GS and will necessarily produce the targeted O-GS photoproduct.

V. Reverse RuO $\rightarrow$ RuP isomerization. Only the RuP to RuO isomerization has been discussed so far. The purpose of this subsection is to discuss the thermal and photochemical reversibility of this isomerization.

The overall barrier height on the ground-state surface for the $\mathrm{O}$-GS $\rightarrow P$-GS process has been computed at 90 $\mathrm{kJ} . \mathrm{mol}^{-1}$ in acetonitrile. This value is comparable to backward thermal barriers found in various photochromic systems for which the lifetime of the metastable photoproduct has been experimentally measured to several hours in solution. ${ }^{80,81}$ The thermal bistability of the $[\mathrm{Ru} \text { (tpy)(bpy)(POPh) }]^{2+}$ complex is an important property for the design of new photoactive devices.

Upon photoexcitation of the RuO isomer, the initial excited state will relax to the triplet O-MLCT state, which was described before. The photoreversible isomerization will require reaching $P$-MECP for which a pathway was found towards the $P$-GS. This means overcoming two successive barriers, O-MLCT $\rightarrow O-M C$ and $O-M C \rightarrow P-M L C T / M C$, at 47 and $38 \mathrm{~kJ} \mathrm{~mol}^{-1}$ respectively, and without decaying at the $\mathrm{O}-\mathrm{MECP}_{1}$ and $\mathrm{O}-\mathrm{MECP}_{2}$. Thus, the reverse photoisomerization is unlikely and only thermal backward isomerization is expected.

VI. Solvation effects. We discuss here the main effects of the acetonitrile solvent on the ground- and excited-state free energy profiles. Both are stabilized in acetonitrile on

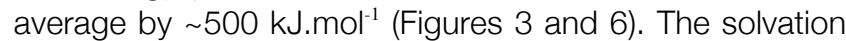
does not appear to have a significant impact on the structures of the various stationary points (Tables 1 and 3 compared to Tables S20 and S21). The overall topology of the ground and excited-state free energy profiles also looks similar.

Concerning the ground-state profile (Figure 3), it is worth noting that the relative free energy between the $P$-GS and

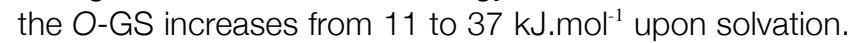
In the triplet excited-state profile (Figure 6), the most noticeable difference concerns the relative energy of the $\mathrm{O}$ $\mathrm{MC}$ state. This state is found at $57 \mathrm{~kJ} \mathrm{~mol}^{-1}$ above the $P$ MLCT/MC minimum in acetonitrile, whereas it was located at nearly the same energy in the gas phase. Similarly, $\mathrm{O}$ $\mathrm{MC}$ was found $75 \mathrm{~kJ} \mathrm{~mol}^{-1}$ above the O-MLCT minimum in

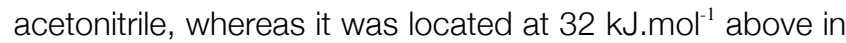
the gas phase. As a consequence, the adiabatic barrier for step 3 has decreased substantially from $15 \mathrm{~kJ} \mathrm{~mol}^{-1}$ in the gas phase to $2 \mathrm{~kJ} \mathrm{~mol}^{-1}$ in acetonitrile. This is a consequence of the larger solvent stabilization of the MLCT states relative to that of the $\mathrm{MC}$ states. It is also worth noting a substantial geometry change for $\mathrm{O}-\mathrm{MC}$ in acetonitrile (Tables 3 and S21). An increase of the Ru-O bond length in O-MC from $2.525 \AA$ in the gas phase to $2.630 \AA$ in acetonitrile and a change of the $\mathrm{C}_{1}-\mathrm{P}-\mathrm{O}-\mathrm{Ru}$ dihedral angle from $-168^{\circ}$ in the gas phase to $-71^{\circ}$ in acetonitrile is observed. In fact, two conformers for O-MC were found in acetonitrile, one of which is similar to the gas phase structure with a dihedral angle $\mathrm{C}_{1}-\mathrm{P}-\mathrm{O}-\mathrm{Ru}=-165^{\circ}$ and the $\mathrm{Ru}-$ $\mathrm{O}$ bond length of $2.606 \AA$. This last conformer is only 3 $\mathrm{kJ} \mathrm{mol}^{-1}$ above the lowest $\mathrm{O}-\mathrm{MC}$ minimum reported in Table S21.

\section{CONCLUSION \& FUTURE WORK}

In summary, the DFT-based computational investigation reported here describes the thermal and photochemical isomerization mechanism from a terminal $P$-bound phosphinidene oxide metal complex $[\mathrm{Ru}(\mathrm{tpy})(\mathrm{bpy})(\mathrm{POPh})]^{2+}$ to the corresponding O-bound metal complex $[\mathrm{Ru} \text { (tpy)(bpy)(OPPh) }]^{2+}$. The main result is that the thermal isomerization is both kinetically and thermodynamically unfavorable, whereas photoisomerization can readily take place either by adiabatic or nonadiabatic routes. The bistability of the complex along with the fact that both isomers have different absorption properties (different colors) make this complex a promising candidate for photochromic devices.

The adiabatic mechanism is based on a triplet potential energy profile that connects various excited states of the two isomers. Although this mechanism can lead to the photoproduct formation, the location of triplet/singlet funnels in the vicinity of the lowest energy minima along the excited-state profile will favor the nonadiabatic pathways. We have shown that upon nonradiative decay (intersystem crossing) at these funnels, the photoisomerization can complete on the ground state PES. Another consequence of the presence of these funnels will be the absence of luminescence in this system.

The reverse RuO to RuP isomerization was found to be achievable only thermally. The backward isomerization barrier is relatively large allowing the photoproduct to be long-lived (several hours), as found for example in ruthenium sulfoxide complexes. ${ }^{81}$

The predictive computational results reported in the present article are very encouraging and experimental studies on the linkage isomerism of $[R u(t p y)(b p y)(R P O)]^{2+}$ complexes are now under active investigations in the group of $A$. Igau. We would like to point out that the photoisomerization channel was the focus of this mechanistic study, but other competing processes such as ligand photodissociation or photosubstitution can also be involved. Considering the high ionic character of the $\mathrm{P}-\mathrm{O}$ bond in this complex, acid-base reactivity with protic solvent cannot be excluded. ${ }^{34}$ This aspect should be investigated in future experimental and theoretical work. Thus, it would be highly interesting to extend the studies to chalcogenophosphinidene ligands $R P=X$ with $X=S$ and $S e$. 


\section{ASSOCIATED CONTENT}

\section{SUPPORTING INFORMATION}

Tables S1-S15 for optimized cartesian coordinates and electronic structures of all the stationary points. Table S16 for the NPA in $P$-GS and O-GS. Tables S17-S18 for strongest oscillator strength transitions in P-GS and O-GS. Table S19 for main geometrical parameters of $P-M C$ and $O-M_{2}$ structures. Tables S20-S21 for main geometrical parameters of ground- and excited-state structures optimized in acetonitrile. Table S22 for geometrical parameters and energies of the singlet/triplet MECPs. Figures S1-S3 for relaxation pathways from MECPs. Figure S4 for structures of all the transition states. Figures S5-S7 for results of IRC calculations.

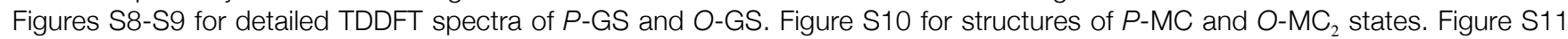
for complete ground- and excited-state profiles along thermal isomerization and photoisomerization pathways. Figures $\mathrm{S} 12$ and $\mathrm{S} 13$ for ground- and excited-state free energy profiles in vacuum and in acetonitrile. This material is available free of charge via the Internet at http://pubs.acs.org.

\section{AUTHOR INFORMATION \\ Corresponding Author}

martial.boggio@irsamc.ups-tlse.fr

alain.igau@lcc-toulouse.fr

\section{ACKNOWLEDGEMENT}

This work was performed under the ANR PhosphoRulr program. It was granted access to the HPC resources of CALMIP under the allocation 2012-p1041.

\section{REFERENCES}

${ }^{1}$ Szacilowski, K. Digital Information Processing in Molecular Systems. Chem. Rev. 2008, 108, 3481-3548.

${ }^{2}$ Andréasson, J.; Pischel, U. Smart Molecules at Work-Mimicking Advanced Logic Operations. Chem. Soc. Rev. 2010, 39, 174-188.

${ }^{3}$ Dürr, H.; Bouas-Laurent, H., Eds. Photochromism: Molecules and Systems; Elsevier: Amsterdam, 1990.

${ }^{4}$ Bouas-Laurent, H.; Dürr, H. Organic Photochromism. Pure Appl. Chem. 2001, 73, 639-665.

${ }^{5}$ Irie, M. Diarylethenes for Memories and Switches. Chem. Rev. 2000, 100, 1685-1716.

${ }^{6}$ Yokoyama, Y. Fulgides for Memories and Switches. Chem. Rev. 2000, 100, 1717-1739.

${ }^{7}$ Berkovic, G.; Krongauz, V.; Weiss, V. Spiropyrans and Spirooxazines for Memories and Switches. Chem. Rev. 2000, 100, 17411753.

${ }^{8}$ Crano, J. C.; Guglielmetti, R. J. Organic Photochromic and Thermochromic Compounds; Plenum Press: New York and London, 1998.

${ }^{9}$ Gütlich, P.; Garcia, Y.; Woike, T. Photoswitchable Coordination Compounds. Coord. Chem. Rev. 2001, 219-221, 839-879.

${ }^{10}$ Rack, J. J. Excited State Isomerization in Photochromic Ruthenium Complexes. Z. Kristallogr. 2008, 223, 356-362.

${ }^{11}$ Rack, J. J. Electron Transfer Triggered Sulfoxide Isomerization in Ruthenium and Osmium complexes. Coord. Chem. Rev. 2009, $253,78-85$.

${ }^{12}$ McClure, B. A.; Rack, J. J. Isomerization in Photochromic Ruthenium Sulfoxide Complexes. Eur. J. Inorg. Chem. $2010,3895-3904$.

${ }^{13}$ Bitterwolf, T. E. Photochemical Nitrosyl Linkage Isomerism/Metastable States. Coord. Chem. Rev. 2006, 250, $1196-1207$.

${ }^{14}$ Coppens, P.; Novozhilova, I.; Kovalevsky, A. Photoinduced Linkage Isomers of Transition-Metal Nitrosyl Compounds and Related Complexes. Chem. Rev. 2002, 102, 861-883.

${ }^{15}$ To, T. T.; Duke, C. B.; Junker, C. S.; O'Brien, C. M.; Ross, C. R.; Barnes, C. E.; Webster, C. E.; Burkey, T. J. Linkage Isomerization as a Mechanism for Photochromic Materials: Cyclopentadienylmanganese Tricarbonyl Derivatives with Chelatable Functional Groups. Organometallics 2008, 27, 289-296.

${ }^{16}$ Kume, S.; Nishihara, H. Photochrome-Coupled Metal Complexes: Molecular Processing of Photon Stimuli. Dalton Trans. 2008, 25, 3260-3271.

${ }^{17}$ Smith, M. K.; Gibson, J. A.; Young, C. G.; Broomhead, J. A.; Junk, P. C.; Keene, F. R. Photoinduced Ligand Isomerization in Dimethyl Sulfoxide Complexes of Ruthenium(II). Eur. J. Inorg. Chem. 2000, 1365-1370.

${ }^{18}$ Rack, J. J.; Winkler, J. R.; Gray, H. B. Phototriggered Ru(II)-dimethylsulfoxide Linkage Isomerization in Crystals and Films. J. Am. Chem. Soc. 2001, 123, 2432-2433. 
${ }^{19}$ Rack, J. J.; Mockus, N. V. Room-Temperature Photochromism in cis- and trans-[Ru(bpy) $\left.{ }_{2}(\mathrm{dmso})_{2}\right]^{2+}$. Inorg. Chem. 2003, 42, 57925794.

${ }^{20}$ McClure, B. A.; Mockus, N. V.; Butcher, D. P.; Lutterman, D. A.; Turro, C.; Petersen, J. L.; Rack, J. J. Photochromic Ruthenium Sulfoxide Complexes: Evidence for Isomerization Through a Conical Intersection. Inorg. Chem. 2009, 48, 8084-8091.

${ }^{21}$ McClure, B. A.; Rack, J. J. Two-Color Reversible Switching in a Photochromic Ruthenium Sulfoxide Complex. Angew. Chem. Int. Ed. $2009,48,8556-8558$.

22 Johnson, D. A.; Dew, V. C. Photochemical Linkage Isomerization in Coordinated SO $\mathrm{SO}_{2}$ Inorg. Chem. 1979, $18,3273-3274$.

${ }^{23}$ Sylvester, S. O.; Cole, J. M.; Waddell, P. G. Photoconversion Bonding Mechanism in Ruthenium Sulfur Dioxide Linkage Photoisomers Revealed by in Situ Diffraction. J. Am. Chem. Soc. 2012, 134, 11860-11863.

${ }^{24}$ Börner, A., Ed. Phosphorus Ligands in Asymmetric Catalysis, Synthesis and Applications; Wiley-VCH: Weinheim, 2008.

${ }^{25}$ Caspar, J. V.; Meyer, T. J. Photochemistry of MLCT Excited-States. Effect of Nonchromophoric Ligand Variations on Photophysical Properties in the Series cis-Ru(bpy $)_{2} \mathrm{~L}_{2}{ }^{2+}$. Inorg. Chem. 1983, 22, 2444-2453.

${ }^{26}$ Fletcher, N. C.; Keene, F. R. New Synthetic Route to Monocarbonyl Polypyridyl Complexes of Ruthenium: their Stereochemistry and Reactivity. J. Chem. Soc., Dalton Trans. 1998, 14, 2293-2301.

${ }^{27}$ Dixon, I. M.; Lebon, E.; Sutra, P.; Igau, A. Luminescent Ruthenium-Polypyridine Complexes \& Phosphorus Ligands: Anything but a Simple Story. Chem. Soc. Rev. 2009, 38, 1621-1634.

${ }^{28}$ Lebon, E.; Bastin, S.; Sutra, P.; Vendier, L.; Piau, R. E.; Dixon, I. M.; Boggio-Pasqua, M.; Alary, F.; Heully, J.-L.; Igau, A.; et al. Can a Functionalized Phosphine Ligand Promote Room Temperature Luminescence of the $[\mathrm{Ru}(\mathrm{bpy})(\mathrm{tpy})]^{2+}$ Core? Chem. Commun. 2012, 48, 741-743.

${ }^{29}$ Dixon, I. M.; Lebon, E.; Loustau, G.; Sutra, P.; Vendier, L.; Igau, A.; Juris, A. Broad HOMO-LUMO Gap Tuning Through the Coordination of a Single Phosphine, Aminophosphine or Phosphite onto a [Ru(tpy)(bpy)] ${ }^{2+}$ Core. Dalton Trans. $2008,5627-5635$.

${ }^{30}$ Niecke, E.; Engelmann, M.; Zorn, H.; Krebs, B.; Henkel, G. Phosphazenes of Coordination Number 2 and Number 3, Part 19. Complex-Stabilization of an aminooxophosphane (Phosphinidene Oxide). Angew. Chem., Int. Ed. Engl. 1980, 19, 710-712.

${ }^{31}$ Hitchcock, P. B.; Johnson, J. A.; Lemos, M. A. N. D. A.; Meidine, M. F; Nixon, J. F.; Pombeiro, A. J. L. Novel Synthesis of a Phosphinidene Oxide- $\mathrm{P}\left(\mathrm{RP}=\mathrm{O}, \mathrm{R}=\mathrm{Bu}^{\mathrm{t}} \mathrm{CH}_{2}-\right)$ Complex of Rhenium(I) from a Phosphaalkyne Precursor. Crystal and Molecular Structure of $\left[\mathrm{ReCl}\left(\mathrm{Ph}_{2} \mathrm{PCH}_{2} \mathrm{CH}_{2} \mathrm{PPh}_{2}\right)_{2}\left\{\mathrm{P}(\mathrm{O}) \mathrm{CH}_{2} \mathrm{Bu}^{\mathrm{t}}\right\}\right]$. J. Chem. Soc., Chem. Commun. 1992, 645-646.

${ }^{32}$ Alonso, M.; García, M. E.; Ruiz, M. A.; Amidov, H.; Jeffery, J. C. Chemistry of the Phosphinidene Oxide Ligand. J. Am. Chem. Soc. 2004, 126, 13610-13611.

33 Alvarez, M. A.; García, M. E.; González, R.; Ramos, A.; Ruiz, M. A. Chemical and Structural Effects of Bulkness on BentPhosphinidene Bridges: Synthesis and Reactivity of the Diiron Complex $\left[\mathrm{Fe}_{2} \mathrm{Cp}_{2}\left\{\mu-\mathrm{P}\left(2,4,6-\left(\mathrm{C}_{6} \mathrm{H}_{2}{ }^{\mathrm{t}} \mathrm{Bu} \mathrm{u}_{3}\right)\right\}(\mu-\mathrm{CO})(\mathrm{CO})_{2}\right]\right.$. Organometallics 2010, 29, 1875-1878.

${ }^{34}$ Alonso, M.; Alvarez, M. A.; García, M. E.; García-Vivo, D.; Ruiz, M. A. Chemistry of the Oxophosphinidene Ligand. 1. Electronic Structure of the Anionic Complexes $\left.\left[\mathrm{MCp}\left\{\mathrm{P}(\mathrm{O}) \mathrm{R}^{\star}\right\}(\mathrm{CO})_{2}\right)\right]^{-}\left(\mathrm{M}=\mathrm{Mo}, \mathrm{W} ; \mathrm{R}^{\star}=2,4,6-\mathrm{C}_{6} \mathrm{H}_{2}{ }^{\mathrm{t}} \mathrm{Bu}_{3}\right)$ and Their Reactions with $\mathrm{H}^{+}$and $\mathrm{C}-\mathrm{Based}$ Electrophiles. Inorg. Chem. 2010, 49, 8962-8976.

${ }^{35}$ Alonso, M.; Alvarez, M. A.; García, M. E.; Ruiz, M. A.; Hamidov, H.; Jeffery, J. C. Chemistry of the Oxophosphinidene Ligand. 2. Reactivity of the Anionic Complexes $\left.\left[\mathrm{MCp}\left\{\mathrm{P}(\mathrm{O}) \mathrm{R}^{*}\right\}(\mathrm{CO})_{2}\right)\right]^{-}\left(\mathrm{M}=\mathrm{Mo}, \mathrm{W} ; \mathrm{R}^{*}=2,4,6-\mathrm{C}_{6} \mathrm{H}_{2}{ }^{\mathrm{t}} \mathrm{Bu}_{3}\right)$ Toward Electrophiles Based on Elements Different from Carbon. Inorg. Chem. 2010, 49, 11595-11605.

${ }^{36}$ Ciofini, I.; Daul, C. A.; Adamo, C. Phototriggered Linkage Isomerization in Ruthenium-Dimethylsulfoxyde Complexes: Insights from Theory. J. Phys. Chem. A 2003, 107, 11182-11190.

37 Göttle, A. J.; Dixon, I. M.; Alary, F.; Heully, J.-L.; Boggio-Pasqua, M. Adiabatic Versus Nonadiabatic Photoisomerization in Photochromic Ruthenium Sulfoxide Complexes: A Mechanistic Picture from Density Functional Theory Calculations. J. Am. Chem. Soc. $2011,133,9172-9174$

38 Österman, T.; Abrahamsson, M.; Becker, H.-C.; Hammarström, L.; Persson, P. Influence of Triplet State Multidimensionality on Excited State Lifetimes of Bis-tridentate Ru-II Complexes: A Computational Study. J. Phys. Chem. A 2012, 116, 1041-1050.

39 Indelli, M.T.; Carli, S.; Ghirotti, M.; Chiorboli, C.; Ravaglia, M.; Garavelli, M.; Scandola, F. Triplet Pathways in Diarylethene Photochromism: Photophysical and Computational Study of Dyads Containing Ruthenium(II) Polypyridine and 1,2-Bis(2methylbenzothiophene-3-yl)maleimide Units. J. Am. Chem. Soc. 2008, 130, 7286-7299.

${ }^{40}$ Frisch, M. J.; Trucks, G. W.; Schlegel, H. B.; Scuseria, G. E.; Robb, M. A.; Cheeseman, J. R.; Scalmani, G.; Barone, V.; Mennucci, B.; Petersson, G. A.; et al. Gaussian 09, Revision A.2, Gaussian, Inc., Wallingford CT, 2009.

${ }^{41}$ Zhao, Y.; Truhlar, D. G. Hybrid Meta Density Functional Theory Methods for Thermochemistry, Thermochemical Kinetics, and Noncovalent Interactions: The MPW1B95 and MPWB1K Models and Comparative Assessments for Hydrogen Bonding and van der Waals Interactions. J. Phys. Chem. A 2004, 108, 6908-6918.

42 Dunning, Jr, T. H.; Hay, P. J. Modern Theoretical Chemistry; Plenum: New York, 1976; pp 1-28.

${ }^{43}$ Hay, P. J.; Wadt, W. R. Ab Initio Effective Core Potentials for Molecular Calculations. Potentials for K to Au Including the Outermost Core Orbitals. J. Chem. Phys. 1985, 82, 299-310.

${ }^{44}$ Hehre, W. J.; Ditchfield, R.; Pople, J. A. Self-Consistent Molecular Orbital Methods. XII. Further Extensions of Gaussian-Type Basis Sets for Use in Molecular Orbital Studies of Organic Molecules. J. Chem. Phys. 1972, 56, 2257-2261.

${ }^{45}$ Hariharan, P. C.; Pople, J. A. The Influence of Polarization Functions on Molecular Orbital Hydrogenation Energies. Theor. Chim. Acta $1973,28,213-222$.

${ }^{46}$ Francl, M. M.; Pietro, W. J.; Hehre, W. J.; Binkley, J. S.; Gordon, M. S.; DeFrees, D. J.; Pople, J. A. Self-Consistent Molecular Orbital Methods. XXIII. A Polarization-Type Basis Set for Second-Row Elements. J. Chem. Phys. 1982, 77, 3654-3665.

${ }^{47}$ Andrae, D.; Häussermann, U.; Dolg, M.; Stoll, H.; Preuss, H. Energy-Adjusted Ab Initio Pseudopotentials for the Second and Third Row Transition Elements. Theor. Chim. Acta 1990, 77, 123-141. 
${ }^{48}$ Schäfer, A.; Horn, H.; Ahlrichs, R. Fully Optimized Contracted Gaussian-Basis Sets for Atoms Li to Kr. J. Chem. Phys. 1992, 97, $2571-2577$.

${ }^{49}$ Reed, A. E.; Curtiss, L. A.; Weinhold, F. Intermolecular Interactions from a Natural Bond Orbital, Donor-Acceptor Viewpoint. Chem. Rev. 1988, 88, 899-926.

${ }^{50}$ Adamo, C.; Barone, V. Toward Reliable Density Functional Methods Without Adjustable Parameters: The PBE0 Model. J. Chem. Phys. 1999, 110, 6158-6169.

${ }^{51}$ Martin, R. L. Natural Transition Orbitals. J. Chem. Phys. 2003, 118, 4775-4777.

${ }^{52}$ Dreuw, A.; Head-Gordon, M. Single-Reference Ab Initio Methods for the Calculation of Excited States of Large Molecules. Chem. Rev. 2005, 105, 4009-4037.

${ }^{53}$ Monari, A.; Very, T.; Rivail, J.-L.; Assfeld, X. A QM/MM Study on the Spinach Plastocyanin: Redox Properties and Absorption Spectra. Comp. Theor. Chem. 2012, 990, 119-125.

${ }^{54}$ Chantzis, A.; Very, T.; Monari, A.; Assfeld, X. Improved Treatment of Surrounding Effects: UV/vis Absorption Properties of a Solvated Ru(II) Complex. J. Chem. Theory Comput. 2012, 8, 1536-1541.

${ }^{55}$ Guillon, T.; Boggio-Pasqua, M.; Alary, F.; Heully, J.-L.; Lebon, E.; Sutra, P.; Igau, A. Theoretical Investigation on the Photophysical Properties of Model Ruthenium Complexes with Diazabutadiene Ligands $\left[R u(b p y)_{3-x}(d a b)_{x}\right]^{2+}(x=1-3)$. Inorg. Chem. $2010,49,8862-8872$.

${ }^{56}$ Neese, F.; Becker, U.; Ganyushin, D.; Liakos, D.; Kossmann, S.; Petrenko, T.; Riplinger, C.; Wennmohs, F. ORCA; Universität Bonn, 2009

${ }^{57}$ Grimme, S.; Antony, J.; Ehrlich, S.; Krieg, H. A Consistent and Accurate Ab Initio Parametrization of Density Functional Dispersion Correction (DFT-D) for the 94 elements H-Pu. J. Chem. Phys. 2010, 132, 154104.

58 Tomasi, J.; Mennucci, B.; Cammi, R. Quantum Mechanical Continuum Solvation Models. Chem. Rev. 2005, 105, $2999-3094$.

${ }^{59}$ Heully, J.-L.; Alary, F.; Boggio-Pasqua, M. Spin-Orbit Effects on the Photophysical Properties of Ru(bpy) ${ }_{3}^{2+}$. J. Chem. Phys. 2009, $131,184308$.

${ }^{60}$ Borg, O. A.; Godinho, S. S. M. C.; Lundqvist, M. J.; Lunell, S.; Persson, P. Computational Study of the Lowest Triplet State of Ruthenium Polypyridyl Complexes Used in Artificial Photosynthesis. J. Phys. Chem. A 2008, 112, 4470-4476.

${ }^{61}$ Vallett, P. J.; Damrauer, N. H. Experimental and Computational Exploration of Ground and Excited State Properties of Highly Strained Ruthenium Terpyridine Complexes. J. Phys. Chem. A 2013, 117, 6489-6507.

62 Breivogel, A.; Meister, M.; Förster, C.; Laquai, F.; Heinze, K. Excited State Tuning of Bis(tridentate) Ruthenium(II) Polypyridine Chromophores by Push-Pull Effects and Bite Angle Optimization: A Comprehensive Experimental and Theoretical Study. Chem. Eur. J. 2013, 19, 13745-13760.

${ }^{63}$ Derrah, E. J.; Pantazis, D. A.; McDonald, R.; Rosenberg, L. A Highly Reactive Ruthenium Phosphido Complex Exhibiting Ru-P $\pi-$ Bonding. Organometallics 2007, 26, 1473-1482.

${ }^{64}$ Wang, J.-C.; Lin, R.-C.; Chi, Y.; Peng, S.-M.; Lee, G.-H. High-Nuclearity Phosphinidene Clusters. Synthesis, Characterization, and Reactivity of two $\mathrm{W}_{2} \mathrm{Ru}_{4}$ Clusters with a $\mu_{4}-\eta^{2}$-CO Ligand. Organometallics 1993, 12, 4061-4066.

65 Yamada , K.; Koga, N. Variationally Determined Electronic States for the Theoretical Analysis of Intramolecular Interaction. II. Qualitative Nature of the P-O Bond in Phosphine Oxides. J. Comput. Chem. 2013, 34, 149-161.

${ }^{66}$ Chesnut, D. B.; Savin, A. The Electron Localization Function (ELF) Description of the PO Bond in Phosphine Oxide. J. Am. Chem. Soc. $1999,121,2335-2336$.

${ }^{67}$ Gilheany, D. G. The Chemistry of Organophosphorus Compounds; John Wiley and Sons Ltd.: New York, $1992 ;$ Vol. 2.

${ }^{68}$ Gilheany, D. G. No d-Orbitals but Walsh Diagrams and Maybe Banana Bonds: Chemical Bonding in Phosphines, Phosphine Oxides, and Phosphonium Ylides. Chem. Rev. 1994, 94, 1339-1374.

${ }^{69}$ Lyssenko K. A.; Grintselev-Knyazev, G. V.; Antipin, M. Y. Nature of the P-O bond in Diphenylphosphonic Acid: Experimental Charge Density and Electron Localization Function Analysis. Mendeleev Communications 2002, 12, 128-130.

${ }^{70}$ Gamoke, B.; Neff, D.; Simons, J. Nature of PO Bonds in Phosphates. J. Phys. Chem. A 2009, 113, 5677-5684.

${ }^{71}$ Reed, A. E.; von Ragué Schleyer, P. Chemical Bonding in Hypervalent Molecules - The Dominance of lonic Bonding and Negative Hyperconjugation over d-Orbital Participation. J. Am. Chem. Soc. 1990, 112, 1434-1445.

${ }^{72}$ Huheey, J. E.; Keiter, E. A.; Keiter, R. L. Inorganic Chemistry, 4th ed.; Harper, Collins: New York, NY, 1993; pp 869-870.

${ }^{73}$ Carducci, M. D.; Pressprich, M. R.; Coppens, P. Diffraction Studies of Photoexcited Crystals: Metastable Nitrosyl-Linkage Isomers of Sodium Nitroprusside. J. Am. Chem. Soc. 1997, 119, 2669-2678.

${ }^{74}$ Coppens, P.; Fomitchev, D. V.; Carducci, M. D.; Culp, K. Crystallography of Molecular Excited States. Transition-Metal Nitrosyl Complexes and the Study of Transient Species. J. Chem. Soc, Dalton Trans. 1998, 6, 865-872.

75 Fomitchev, D. V.; Novozhilova, I.; Coppens, P. Photo-Induced Linkage Isomerism of Transition Metal Nitrosyl and Dinitrogen Complexes Studied by Photocrystallographic Techniques. Tetrahedron 2000, 56, 6813-6820.

76 Johnson, D. A.; Pashman, K. A. Low-Temperature Transients in Solid-State Photochemical Linkage Isomerization of $\left[\mathrm{Co}\left(\mathrm{NH}_{3}\right)_{5} \mathrm{NO}_{2}\right] \mathrm{Cl}_{2}$. Inorg. Nucl. Chem. Lett. 1975, 11, 23-28.

77 Yersin, H.; Donges, D. Low-Lying Electronic States and Photophysical Properties of Organometallic Pd(II) and Pt(II) Compounds. Modern Research Trends Presented in Detailed Case Studies. Top. Curr. Chem. 2001, 214, 81-186.

${ }^{78}$ Alary, F.; Heully, J.-L.; Bijeire, L.; Vicendo, P. Is the ${ }^{3}$ MLCT the Only Photoreactive State of Polypyridyl Complexes? Inorg. Chem. 2007, 46, 3154-3165.

${ }^{79}$ Alary, F.; Boggio-Pasqua, M.; Heully, J.-L.; Marsden, C. J; Vicendo, P. Theoretical Characterization of the Lowest Triplet Excited States of the Tris-(1,4,5,8-tetraazaphenanthrene) Ruthenium Dication Complex. Inorg. Chem. 2008, 47, 5259-5266.

${ }^{80}$ Ern, J.; Petermann, M.; Mrozek, T.; Daub, J.; Kuldova, K.; Kryschi, C. Dihydroazulene/Vinylheptafulvene Photochromism: Dynamics of the Photochemical Ring-Opening Reaction. Chem. Phys. 2000, 259, 331-337. 
${ }^{81}$ Dieckmann, V.; Eicke, S.; Rack, J. J.; Woike, T.; Imlau, M. Pronounced Photosensitivity of Molecular $\left.[\text { Ru(bpy })_{2}(\mathrm{OSO})\right]^{+}$Solutions Based on Two Photoinduced Linkage Isomers. Opt. Express 2009, 17, 15052-15060. 
Table of Content

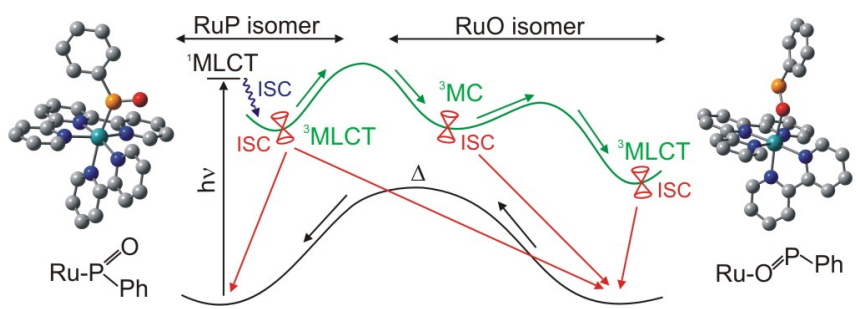

